\title{
Evolution of zincian malachite synthesis by low temperature co- precipitation and its catalytic impact on the methanol synthesis
}

Leon Zwiener ${ }^{\mathrm{a}}$, Frank Girgsdies ${ }^{\mathrm{a}}$, Daniel Brennecke ${ }^{\mathrm{a}}$, Detre Teschner ${ }^{\mathrm{a}, \mathrm{b}}$, Albert G.F. Machoke ${ }^{\mathrm{b}}$, Robert Schlögl ${ }^{\mathrm{a}, \mathrm{b}}$, and Elias Frei*a

[a] Department of Inorganic Chemistry, Fritz Haber Institute of the Max Planck Society, Faradayweg 4-6, 14195 Berlin, Germany.

[b] Department of Heterogeneous Reactions, Max Planck Institute for Chemical Energy Conversion, Stiftstrasse 34 - 36, 45470 Mülheim an der Ruhr, Germany.

*E-mail: efrei@ fhi-berlin.mpg.de

Keywords: zincian malachite $\cdot$ co-precipitation $\bullet$ methanol synthesis

\begin{abstract}
Low temperature co-precipitation enabled, for the first time, the preparation of phase pure zincian malachite precursors with $\mathrm{Zn}$ contents of up to 31 at.- $\%$. The high $\mathrm{Zn}$ content was beneficial for maximizing the dispersion of $\mathrm{Cu}$ and oxygen defect sites on the $\mathrm{ZnO}$ surface. Further, an increase of the $\mathrm{Zn}$ loading from 10 to 31 at.-\% doubled the specific surface areas obtained from $\mathrm{N}_{2} \mathrm{O}-\mathrm{RFC}$ (Reactive Frontal Chromatography) and $\mathrm{H}_{2}$ TA (Transient Adsorption). As the Zn content was increased from 10 to 31 at.-\%, the apparent activation energy for methanol formation was strongly decreased. Furthermore, water formation was reduced indicating a retardation of the rWGS in favor of methanol formation at high Zn loadings. Additionally, compared to high temperature co-precipitation, low temperature precipitated catalysts exhibited increased catalytic activities.
\end{abstract}

\section{Introduction}

Rising global energy demand, relying on the ongoing consumption of fossil fuels, has led to a drastic increase in atmospheric $\mathrm{CO}_{2}$ concentration over the past century.[1] Since $\mathrm{CO}_{2}$ has been attributed to be the main anthropogenic source of the greenhouse effect, $\mathrm{CO}_{2}$ has become a valuable carbon source available for chemical conversion (e.g. hydrogenation). Hence, the catalytic conversion of $\mathrm{CO}_{2}$ to value added products, particularly to methanol as a key chemical and an important feedstock for the chemical industry [2], offers a promising technique for the utilization of $\mathrm{CO}_{2}$.[3]

Since the invention of the low-pressure methanol synthesis by ICI in 1966, the industrially applied catalyst of choice consists mainly of $\mathrm{Cu}$ and $\mathrm{ZnO}[2,4]$. In addition, this type of $\mathrm{Cu} / \mathrm{ZnO}$-based catalyst is also applied in the low-temperature water-gas-shift reaction and methanol steam reforming [2,5]. Key features of the final catalyst involve the complex interplay of a defective $\mathrm{Cu}$ phase including a large surface area of $\mathrm{Cu}$ and a $\mathrm{ZnO}$ based strong metal support interaction (SMSI) [6-8]. The maximum synergism is reached by a high dispersion of $\mathrm{Cu}$ and $\mathrm{ZnO}$, enhancing their interfacial contact and improving the catalytic activity. A perfect distribution of $\mathrm{Cu}$ and $\mathrm{Zn}$ on the atomic scale is coupled to a phase-pure precursor synthesis concept based on co-precipitation [2, 911]. As it has been demonstrated by a vast number of research studies on this system [12-19], the physiochemical properties of the precursor and thus the final catalyst is crucially affected by the conditions applied during its 
formation. This phenomenon is termed as "chemical memory" [13].

Named after their mineral counterparts, multiple crystalline precursors can be obtained ranging from $\mathrm{Cu}$-rich to $\mathrm{Zn}$-rich compositions, including malachite $\left[\mathrm{Cu}_{2}(\mathrm{OH})_{2} \mathrm{CO}_{3}\right]$, zincian malachite $\left[\left(\mathrm{Cu}_{1-\mathrm{x}} \mathrm{Zn}_{\mathrm{x}}\right)_{2}(\mathrm{OH})_{2} \mathrm{CO}_{3}, \mathrm{x} \leq 0.27\right]$ [20] and aurichalcite $\left[(\mathrm{Cu}, \mathrm{Zn})_{5}(\mathrm{OH})_{6}\left(\mathrm{CO}_{3}\right)_{2}\right]$. A higher degree of $\mathrm{Cu}$ substitution by $\mathrm{Zn}$ than 27 at.-\%, in the zincian malachite lattice was so far not accessible by synthetic procedures [21], but solely present in the naturally occurring rosasite $\left[\left(\mathrm{Cu}_{1-\mathrm{x}} \mathrm{Zn}_{\mathrm{x}}\right)_{2}(\mathrm{OH})_{2} \mathrm{CO}_{3}, 0.3<\mathrm{x}<0.5\right]$ [21].

It is reported that the preferred $\mathrm{Cu} / \mathrm{ZnO}$ ratios are about $70: 30$ for ternary $\mathrm{Cu} / \mathrm{ZnO} / \mathrm{Al}_{2} \mathrm{O}_{3}$ [22] and 2:1 in binary $\mathrm{Cu} / \mathrm{ZnO}$ catalysts [18]. Zincian malachite, derived from crystallization during aging of the initially formed transient amorphous zincian georgeite $[13,23]$, was identified as the most promising precursor phase for the final methanol synthesis catalyst. Due to its crystallization in the form of thin interwoven needles, a favorable highly porous meso-structure is obtained [24]. Moreover, to further increase the $\mathrm{Cu}$ dispersion, exceeding the critical limit of 27 at.- $\% \mathrm{Zn}$ is highly desirable. Hitherto, increasing the $\mathrm{Zn}$ content leads to a phase separated precursor mixture containing zincian malachite and a Zn-rich aurichalcite by-phase. This inhomogeneous precursor structure (platelets and rods) yields a poor catalytic activity $[13,18]$. Generally, the process of co-precipitation is seen as an interplay of saturation, nucleation and particle growth of metastable solids. As a consequence, it is assumed that an increased $\mathrm{Zn}$-incorporation into the zincian malachite structure is also kinetically controlled and thus the appearance of $\mathrm{Zn}$-rich precipitation products is expected to correlate with the precipitation temperature.

In this study, we address the challenge of the limited $\mathrm{Zn}$ incorporation in the malachite lattice by the introduction of independent temperature variables for the initial co-precipitation and subsequent aging step. Low temperature co-precipitation at $278 \mathrm{~K}$ followed by a controlled increase to $338 \mathrm{~K}$ for further aging led to a series of mixed metal hydroxycarbonate precursors. The influence of the chosen synthesis conditions on the phase composition, $\mathrm{Cu} / \mathrm{Zn}$ content in the zincian malachite phase, microstructure and resulting catalytic activity in methanol synthesis are analyzed and compared to a conventional high-temperature co-precipitation approach. All samples were thoroughly analyzed by multiple techniques including powder X-ray diffraction (XRD), X-ray fluorescence spectroscopy (XRF), thermogravimetric analysis (TGA) coupled to evolved gas analysis (EGA), temperature programmed reduction (TPR), scanning electron microscopy (SEM) and transmission electron microscopy (TEM). In addition, the specific surface areas were determined by $\mathrm{N}_{2} \mathrm{O}$-reactive frontal chromatography $\left(\mathrm{N}_{2} \mathrm{O}-\mathrm{RFC}\right)$ and $\mathrm{H}_{2}$-transient adsorption $\left(\mathrm{H}_{2}-\mathrm{TA}\right)$.

\section{Experimental}

2.1 General 
All reagents were purchased from commercial sources and were used without further purification. Ultrapure water was taken from a Milli-Q water treatment system (Merck Millipore) and used for all experiments.

\subsection{Sample preparation}

The samples were prepared by a pH-controlled co-precipitation in an automated reactor setup (LabMax, Mettler-Toledo). The proper amounts of $\mathrm{Cu}\left(\mathrm{NO}_{3}\right)_{2} \times 3 \mathrm{H}_{2} \mathrm{O}(\geq 99 \%$ Carl Roth $\mathrm{GmbH}$, lot: 454217716) and $\mathrm{Zn}\left(\mathrm{NO}_{3}\right)_{2} \times 6 \mathrm{H}_{2} \mathrm{O}(\geq 99,9 \%$, Carl Roth $\mathrm{GmbH}$, lot:105226072) were dissolved in ultrapure water and concentrated $\mathrm{HNO}_{3}$ (10 mL, $\geq 65 \%$, Carl Roth $\mathrm{GmbH}$, lot: 214212677) was added to obtain the metal salt solution (1.0 L, 1.0 M). An appropriate amount of precipitating agent $\mathrm{Na}_{2} \mathrm{CO}_{3}(\geq 99 \%$ Carl Roth $\mathrm{GmbH}$, lot: 156240183) was dissolved in ultrapure water to obtain a $1.6 \mathrm{M}$ solution. The metal salt solution was added to the partially prefilled reaction vessel (400 mL ultrapure water) with $20 \mathrm{mLmin}^{-1}$ at $278 \mathrm{~K}$ while continuously stirring (300 rpm) within $30 \mathrm{~min}$. In order to keep the $\mathrm{pH}$ constant at a value of 6.50 , appropriate amounts of $\mathrm{Na}_{2} \mathrm{CO}_{3}$ solution were added automatically during the co-precipitation step. Next, the temperature was increased to $338 \mathrm{~K}$ at a rate of $1.0 \mathrm{Kmin}^{-1}$. After the $\mathrm{pH}$-drop was observed, aging of the sample continued for $30 \mathrm{~min}$. Then, the sample was filter-collected and washed for several times by suspension in ultrapure water, until the conductivity of the washing medium was below $0.5 \mathrm{mScm}^{-1}$. The solid precursors were obtained by spray drying (B-290, Büchi Labortechnik $\mathrm{GmbH})$. In the case of the two Zn_XX_HT samples, the synthesis was performed at a constant temperature of $338 \mathrm{~K}$ during co-precipitation and aging (75 min).

Calcination in a rotating furnace (XROTATE 700, Xerion Advanced Heating GmbH) with $2 \mathrm{rpm}$ at $603 \mathrm{~K}$ for $3 \mathrm{~h}\left(21 \% \mathrm{O}_{2} / \mathrm{Ar}, 100 \mathrm{mLmin}^{-1}\right)$ yielded the $\mathrm{CuO} / \mathrm{ZnO}$ precatalysts. The final active catalyst was obtained by reduction at $523 \mathrm{~K}$ for $90 \mathrm{~min}$ in $5 \% \mathrm{H}_{2} / \mathrm{Ar}\left(100 \mathrm{mLmin}^{-1}\right)$ prior to catalytic testing.

\subsection{Characterization}

X-ray diffraction (XRD) measurements were performed in Bragg-Brentano geometry on a D8 Advance II theta/theta diffractometer (Bruker AXS), using $\mathrm{Ni}$ filtered $\mathrm{Cu} \mathrm{K \alpha _{1+2 }}$ radiation and a position sensitive energy dispersive LynxEye silicon strip detector. The data was analyzed by full pattern fitting according to the Rietveld method as implemented in the TOPAS software package (TOPAS version 5.0, 1999-2014 Bruker AXS). The diffraction profiles of the precursors exhibited a pronounced anisotropic peak broadening, which was satisfactorily described using a adaption of the Stephens model [25] modified for anisotropic crystallite size broadening (details see [26]).

Wavelength dispersive X-ray fluorescence (WDXRF) measurements were performed in a S4 PIONEER (Bruker AXS) spectrometer. The $40 \mathrm{~mm}$ sample discs used for the measurement were obtained from the solidified glass melt of fused sample powder (100 mg), $\mathrm{LiBr}\left(10 \mathrm{mg}\right.$, Fluxana) and $\mathrm{Li}_{2} \mathrm{~B}_{4} \mathrm{O}_{7}(8.8 \mathrm{~g}$, Fluxana, $>99.8 \%$ ) using a Vulcan 2MA machine (HD Elektronik). The quantification of the data was based on a 10-point reference curve.

The samples' specific surface area was determined by fitting the adsorption data with the BrunauerEmmett-Teller (BET) model [27]. The sorption data were collected from $\mathrm{N}_{2}$ physisorption at liquid nitrogen 
temperature of $77 \mathrm{~K}$ using an Autosorb-6B2-KR (Quantachrome). Prior to measurement, the samples were degassed at 353 - $373 \mathrm{~K}$ for 2-10 h using an Autosorb Degasser setup (Quantachrome). The uncertainty of the BET values is derived by estimating a constant error of $2 \%$. For selected samples, the pore-size distribution was determined according to the Barrett-Joyner-Halenda (BJH) method [28].

The $\mathrm{N}_{2} \mathrm{O}$ chemisorption capacity was determined by applying the reactive frontal chromatography (RFC) based on the method proposed by Chinchen et al. [29]. For each measurement, approximately $100 \mathrm{mg}$ of precatalyst (100-200 $\mu \mathrm{m}$ particle size) were placed in a U-shaped fixed bed reactor. The reduced catalyst was obtained after in-situ reduction at $523 \mathrm{~K}$ for $30 \mathrm{~min}$ in $5 \% \mathrm{H}_{2} / \mathrm{Ar}\left(80 \mathrm{mLmin}^{-1}\right)$. The sample was cooled to room temperature, followed by $\mathrm{Cu}^{0} \mathrm{H}_{2}$-TA and purged with $\mathrm{He}$, then the gas feed was switched to $1 \% \mathrm{~N}_{2} \mathrm{O} / \mathrm{He}$ $\left(10 \mathrm{mLmin}^{-1}\right)$ for the RFC. The experiment was monitored by a quadrupole mass spectrometer (QM200 Omnistar, Pfeiffer) including $\mathrm{N}_{2}(\mathrm{~m} / \mathrm{z} 28)$ and the delayed signal of $\mathrm{N}_{2} \mathrm{O}(\mathrm{m} / \mathrm{z} 44) . \mathrm{N}_{2}$ was formed due to $\mathrm{N}_{2} \mathrm{O}$ decomposition on $\mathrm{Cu}^{0}$ and probing of oxygen vacancies in $\mathrm{ZnO}$ surface or partly reduced zinc species of the catalyst [30, 31] The $\mathrm{N}_{2}$ signal trace was used for the calculation of both the $\mathrm{N}_{2} \mathrm{O}$ chemisorption capacity and the apparent $\mathrm{Cu}^{0}$ surface area $\left(\mathrm{SA}_{\mathrm{N} 2 \mathrm{O}}\right)$. The former was calculated using the $\mathrm{N}_{2} \mathrm{O} / \mathrm{He}$ flow, and the time interval given by the two inflection points of $\mathrm{N}_{2}$ appearance and $\mathrm{N}_{2} \mathrm{O}$ breakthrough. The latter was derived by using a value of $1.47 \cdot 10^{19}$ atoms $\mathrm{m}^{-2}$ for the mean copper surface atom density and assuming a molar stoichiometry of $\mathrm{Cu} / \mathrm{N}_{2} \mathrm{O}=2$ (halfmonolayer coverage with oxygen). The uncertainty of the $\mathrm{SA}_{\mathrm{N} 20}$ values is derived by estimating a constant error of $5 \%$.

$\mathrm{H}_{2}$-transient adsorption measurement $\left(\mathrm{H}_{2}-\mathrm{TA}\right)$ was performed based on the method introduced by Kuld et al. [30]. For each experiment, approximately $100 \mathrm{mg}$ sample (100-200 $\mu \mathrm{m}$ particle size) were used. The measurement was conducted at room temperature in $5 \% \mathrm{H}_{2} / \mathrm{Ar}\left(20 \mathrm{mLmin}^{-1}\right)$ for 1 hour after purging in Argon. $\mathrm{H}_{2}$-TA of all three oxidation states of the $\mathrm{Cu} / \mathrm{ZnO}$ catalysts, namely the precatalyst containing $\mathrm{CuO}$, the reduced sample $(\mathrm{Cu})$ and the partially oxidized sample obtained after $\mathrm{N}_{2} \mathrm{O}-\mathrm{RFC}\left(\mathrm{Cu}_{2} \mathrm{O}\right)$ were recorded using a thermal conductivity detector (TCD) (X-stream X2GP, Emerson Process Management). For the calculation of SA $\mathrm{H}_{\mathrm{H} \text { TA }}$ it was assumed that no $\mathrm{H}_{2}$ is adsorbed on $\mathrm{CuO}$. Furthermore, the difference in area of $\mathrm{CuO}-\mathrm{Cu}$ and $\mathrm{CuO}-\mathrm{Cu}_{2} \mathrm{O}$ profile integrals and a reference TPR experiment of pure $\mathrm{CuO}$ is needed for the quantification of consumed $\mathrm{H}_{2}$. Relating it to the mean copper surface atom density of $1.47 \cdot 10^{19}$ atoms $\mathrm{m}^{-2}$ leads to the $\mathrm{Cu}-\mathrm{SA} \mathrm{H}_{\mathrm{H}-\mathrm{TA}}$. The uncertainty of the SA-н2-тА values is derived by estimating a constant error of $5 \%$.

Thermogravimetric (TG) measurements were performed using a STA 449 C Jupiter thermoanalyzer (Netzsch) under a controlled gas atmosphere $\left(21 \% \mathrm{O}_{2} / \mathrm{Ar}, 100 \mathrm{mLmin}^{-1}\right)$. The evolved gases were analyzed by a quadrupole mass spectrometer (QMS200 Omnistar, Balzers) connected via a quartz capillary heated to $313 \mathrm{~K}$. Each measurement was performed using approximately $20 \mathrm{mg}$ sample in a temperature range of $300-1000 \mathrm{~K}$ $\left(2 \mathrm{Kmin}^{-1}\right)$. Upon cooling to room temperature, the residual powder sample was further analyzed by powder Xray diffraction. All data were analyzed including partial TG and curve smoothing using the NETZSCH Proteus Thermal Analysis software package (Version 6.10).

Temperature-programmed reduction (TPR) experiments were performed following the principles of Monti and Baker [32]. For each measurement, approximately $100 \mathrm{mg}$ of sample were heated at a rate of $6 \mathrm{Kmin}^{-1}$ in a fixed bed reactor to $615 \mathrm{~K}$ in $5 \% \mathrm{H}_{2} / \mathrm{Ar}\left(80 \mathrm{mLmin}^{-1}\right)$. The TPR profile was recorded using a thermal 
conductivity detector (TCD) (X-stream X2GP, Emerson Process Management).

Scanning electron microscopy (SEM) images were taken on a S-4800 SEM (Hitachi) equipped with a field emission gun (FEG) system. The sample was dispersed on a conductive carbon tape (Plano). The SEM was operated at low accelerating voltage $(1.5 \mathrm{kV})$ for increased resolution of the surface features of the sample. Elemental analysis was performed at elevated accelerating voltages $(20 \mathrm{kV})$ using an energy dispersive X-ray spectroscopy (EDX) detector (Bruker) connected to the SEM.

$\mathrm{X}$-ray photoelectron spectra were recorded on selected samples. Prior to the measurement, the precatalysts were pelletized and reduced in $5 \% \mathrm{H}_{2} / \mathrm{Ar}$ at $523 \mathrm{~K}\left(6 \mathrm{Kmin}^{-1}\right)$ for $30 \mathrm{~min}$. After cooling to room temperature, the samples were inertly transferred to a glove box connected to the spectrometer and mounted on the sample holder. They were directly transferred from the glove box to the spectrometer chamber without air contact. The XPS spectra were recorded using non-monochromatized $\mathrm{Al} \mathrm{K} \mathrm{K}_{\alpha}(1486.6 \mathrm{eV})$ excitation and a hemispherical analyzer (Phoibos 150, SPECS). The binding energy scale was calibrated by the standard $\mathrm{Au} 4 \mathrm{f}_{7 / 2}$ and $\mathrm{Cu} 2 \mathrm{p}_{3 / 2}$ procedure. To calculate the elemental composition, the $\mathrm{Cu} / \mathrm{Zn} 2 \mathrm{p}$ core levels and theoretical cross sections from Yeh and Lindau [33] were used.

\subsection{Catalytic Testing}

Methanol synthesis was used as a test reaction to evaluate the catalytic performance of different materials prepared in this work. All tests were conducted in a fixed bed reactor with an inner diameter of $6 \mathrm{~mm}$ and equipped with a thermocouple for in-situ recording of the temperature of the catalyst. The reactor was integrated in a test-rig for continuous catalysts testing. Analysis of reactants and products was performed by using a gas chromatograph from Agilent (Model 7890 N) equipped with a TCD/FID detector, molar sieve and PlotU columns. $300 \mathrm{mg}$ of the catalyst were mixed with $700 \mathrm{mg}$ of $\mathrm{SiO}_{2}$ and placed into in the reactor. A sieve fraction of $100-$ $200 \mu \mathrm{m}$ was used for both the catalysts and $\mathrm{SiO}_{2}$. Prior to actual activity measurements, the catalyst was reduced with 10 vol. $-\% \mathrm{H}_{2} / \mathrm{Ar}$ for $60 \mathrm{~min}$ at $523 \mathrm{~K}$ and using a heating rate of $1 \mathrm{Kmin}^{-1}$. The activated catalysts were tested at 40 bar and $18.75 \mathrm{CO}_{2} / 3.75 \mathrm{CO} / 10 \mathrm{Ar}$ and $67.5 \mathrm{H}_{2}$, a GHSV of $12000^{\mathrm{h}-1}$ and various temperatures (between $463 \mathrm{~K}$ and $523 \mathrm{~K}$ ). The apparent activation energy calculations follow an Arrhenius approach (ln of the rate as a function of the inverse temperature.) 


\section{Results and Discussion}

Table 1. Overview of all prepared samples including elemental and phase composition (XRF, XRD), averages crystallite domain sizes (XRD), specific surface area determined by $\mathrm{N}_{2}$ physisorption $\left(\mathrm{SA}_{\mathrm{BET}}\right), \mathrm{N}_{2} \mathrm{O}$ reactive frontal chromatography $\left(\mathrm{SA}_{\mathrm{N} 2 \mathrm{O}}\right)$ and $\mathrm{H}_{2}$-transient adsorption (SA $\mathrm{H2- \textrm {TA }}$ ). Apparent activation energies $\left(E_{A}\right)$ for $\mathrm{CH}_{3} \mathrm{OH}$ and $\mathrm{H}_{2} \mathrm{O}$ formation including an error based on the deviation of the linear fits are given as well.

\begin{tabular}{|c|c|c|c|c|c|c|c|c|c|c|c|}
\hline \multirow[t]{2}{*}{ Sample } & \multicolumn{2}{|c|}{ Exp. [at.-\%] } & \multirow[t]{2}{*}{ Phase $^{[a]}$} & \multirow{2}{*}{$\begin{array}{l}\text { Domain } \\
{[\mathrm{nm}]^{[\mathrm{b}]}} \\
\text { Precursor }\end{array}$} & \multirow[t]{2}{*}{ size } & \multicolumn{2}{|c|}{$\mathrm{SA}_{\mathrm{BET}}\left[\mathrm{m}^{2} \mathrm{~g}^{-1}\right]$} & \multirow{2}{*}{$\underset{\left.{ }_{1}^{1}\right]}{\mathrm{SA}_{\mathrm{N} 2 O}}\left[\mathrm{~m}^{2} \mathrm{~g}-\right.$} & \multirow[t]{2}{*}{$\mathrm{SA}_{\mathrm{H} 2-\mathrm{TA}}\left[\mathrm{m}^{2} \mathrm{~g}^{-1}\right]$} & \multicolumn{2}{|c|}{$E_{A}\left[\mathrm{kJmol}^{-1}\right]$} \\
\hline & $\mathrm{Cu}$ & $\mathrm{Zn}$ & & & & Precursor & Precatalyst & & & $\mathrm{CH}_{3} \mathrm{OH}$ & $\mathrm{H}_{2} \mathrm{O}^{[\mathrm{c}]}$ \\
\hline $\mathrm{Zn} \_0$ & 100 & 0 & Mlc & 15 & & 37 & 36 & 0.3 & 0 & - & - \\
\hline $\mathrm{Zn} \_10$ & 89.5 & 10.5 & Zlc & 11 & & 59 & 70 & 12.2 & 5.6 & $64 \pm 2.4$ & $98 \pm 2.6$ \\
\hline $\mathrm{Zn} \_20$ & 79.3 & 20.7 & Zlc & 10 & & 76 & 87 & 22.9 & 10.4 & $49 \pm 2.1$ & $67 \pm 2.8$ \\
\hline $\mathrm{Zn} \_25$ & 75.1 & 24.9 & Zlc & 8.4 & & 90 & 95 & - & - & - & - \\
\hline $\mathrm{Zn} \_30$ & 68.8 & 31.2 & Zlc & 6.7 & & 102 & 116 & 26.0 & 12.3 & $41 \pm 0.7$ & $67 \pm 1.3$ \\
\hline $\mathrm{Zn} \_35$ & 65.6 & 34.4 & $\begin{array}{l}\text { Zlc, } \\
\text { Aur }\end{array}$ & - & & 85 & - & - & - & - & - \\
\hline Zn_10_HT & 90.9 & 9.1 & Zlc & 33 & & 10 & 67 & 11.8 & 3.0 & $70 \pm 2.2$ & $135 \pm 3.7$ \\
\hline Zn_20_HT & 79.9 & 20.1 & $\begin{array}{l}\text { Zlc, } \\
\text { Aur }\end{array}$ & 16 & & 51 & 87 & 22.6 & 5.2 & $50 \pm 2.4$ & $80 \pm 2.9$ \\
\hline
\end{tabular}

[a] malachite (Mlc), zincian malachite (Zlc), aurichalcite (Aur). [b]: The crystallite domain size values of the first 20 reflections (XRD) were averaged. [c] The $E_{A}$ of $\mathrm{H}_{2} \mathrm{O}$ is determined from the overall formation rate of $\mathrm{H}_{2} \mathrm{O}$ and is interpreted as an approximation of the rWGS reaction as unwanted side-reaction during the $\mathrm{CH}_{3} \mathrm{OH}$ formation.

A series of samples with varying Cu:Zn molar ratios of 100:0 to 65:35 was prepared by a low temperature coprecipitation approach at a constant $\mathrm{pH}$ during synthesis (Fig. S1). All samples are designated according to their nominal $\mathrm{Zn}$ contents as given in Table 1 (i.e. the sample with a $\mathrm{Cu}-\mathrm{Zn}$ ratio of 70:30 is named as $\mathrm{Zn} \_30$ ). The calcined precursors (oxides) are named as precatalysts. Two additional samples with the suffix "HT" were prepared for reference purpose applying the conventional synthesis temperature procedure (HT, $338 \mathrm{~K}$ ).

\subsection{Synthesis of the precursors}

Shifting the upper limit of $\mathrm{Zn}$ substitution further towards the rosasite domain, the well-established conventional constant $\mathrm{pH}$ co-precipitation synthesis, generally applied at elevated temperatures (323-363 K [34]) is rethought and newly developed. Independent temperature variables for the initial co-precipitation and subsequent aging steps are introduced (all other parameters are kept constant, see experimental section). Fig. 1 exemplarily shows the applied synthesis protocol for the sample series (Table 1, Fig. S2).

Co-precipitation was performed at $278 \mathrm{~K}$ (light colored pattern, Fig. 1), followed by an incremental increase to $338 \mathrm{~K}$ during aging (dark colored pattern, Fig. 1). In general, co-precipitation of zincian malachite samples lead to the initial formation of a transient amorphous zincian georgeite phase, which crystallizes during the aging time in the mother liquor. This crystallization coincides with a minimum in the $\mathrm{pH}$ curve and a steep turbidity increase of the liquor (after around $102 \mathrm{~min}$ in Fig. 1) [24]. Consequently, low-temperature co-precipitation leads to the formation of amorphous Zn-rich nuclei (Fig. S3 and Fig. S4). With increasing Zn content their crystallization event (indicated by the $\mathrm{pH}$ drop) is shifted to a higher temperature $\left(x_{\mathrm{Zn}} \leq 0.1\right)$ respectively, later in 
time (72-103 min, Fig. S2). This transient process thus leads to an individual residence time of the co-precipitated material in the mother liquor for every sample. As it is a function of time and temperature (Fig. 1b), it is assumed that an increased $\mathrm{Zn}$ incorporation into the zincian malachite structure is kinetically controlled and leads to a metastable "oversaturated" state, represented by the Zn-rich samples and their different crystallization behavior. The period after the $\mathrm{pH}$ drop (defined as aging time) was kept constant.

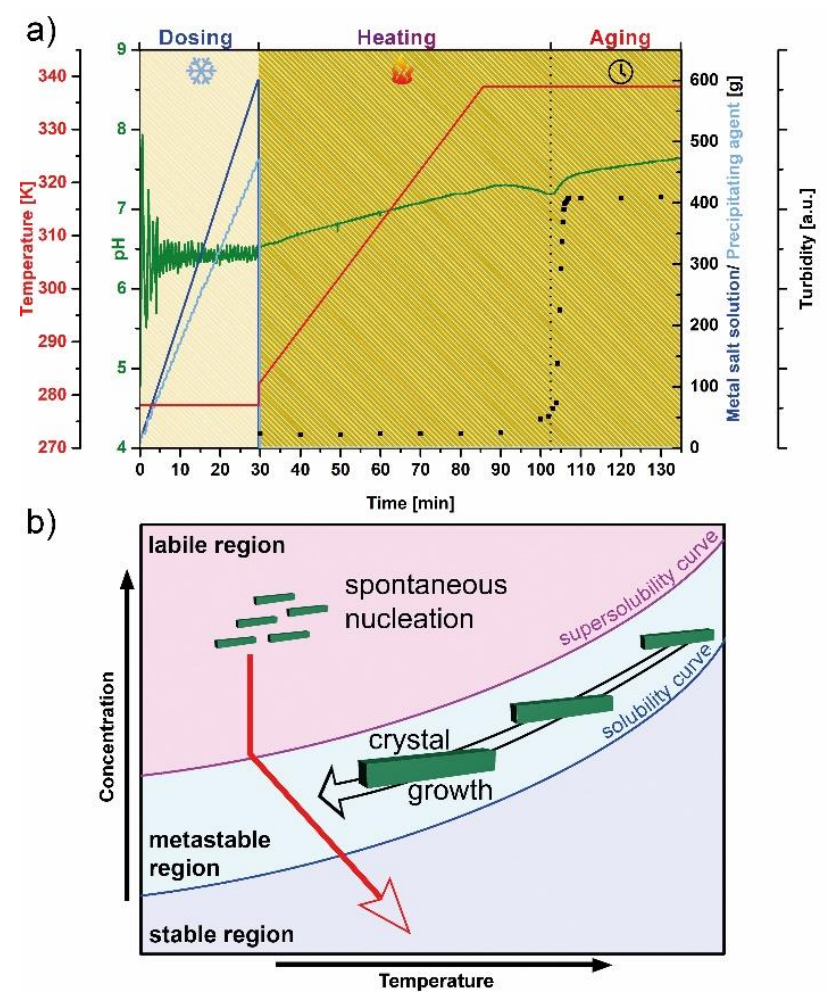

Fig. 1. Synthesis log of sample Zn_30 (a) during dosing/co-precipitation (light shaded), heating and aging time (dark shaded) including temperature (red curve), $\mathrm{pH}$ (green curve), turbidity (symbols), added metal salt solution (blue curve) and precipitating agent (light blue cure). Sketch of solubility- super solubility curves and corresponding occurring processes (b). Synthesis follows the red arrow's trajectory.

\subsection{Characterization of the precursors}

Powder X-ray diffraction data were recorded for the prepared samples featuring nominal molar $\mathrm{Cu} / \mathrm{Zn}$ ratios from 100:0 to 65:35 (Table 1). For the low-temperature co-precipitated samples single-phase synthetic zincian malachite is obtained up to nominal values of $x_{\mathrm{Zn}} \leq 0.3$, as confirmed by the Rietveld fits. Exemplarily, the fit of the $\mathrm{Zn} \_30$ sample is given in Fig. 2. The complete set of Rietveld fits are presented in Fig. S5. The formation of an aurichalcite by-phase is solely observed in the case of the Zn_35 sample (Fig. S5f). The metal composition determined by XRF (Table 1) is close to the nominal value of each sample, yet slightly increased in respect of $\mathrm{Zn}$ content for the phase-pure samples. The incorporation of $\mathrm{Zn}$ into the malachite structure is reflected by the lattice parameters $a, b, c$ and the monoclinic angle $\beta$ and thus allows a qualitative assessment. Fig. 3 (data in Table S2) shows the incremental increase of $\mathrm{Zn}$ by the substitution of $\mathrm{Cu}$ in the (zincian) malachite structure which leads to a Vegard-type linear trend for all lattice parameters in the studied range of $0<x_{\mathrm{Zn}}<0.31$. To the best of the authors' knowledge, the present amount of 31 at.-\% $\mathrm{Zn}$ as part of the phase-pure synthetic zincian malachite reflects the highest value reported to date. 


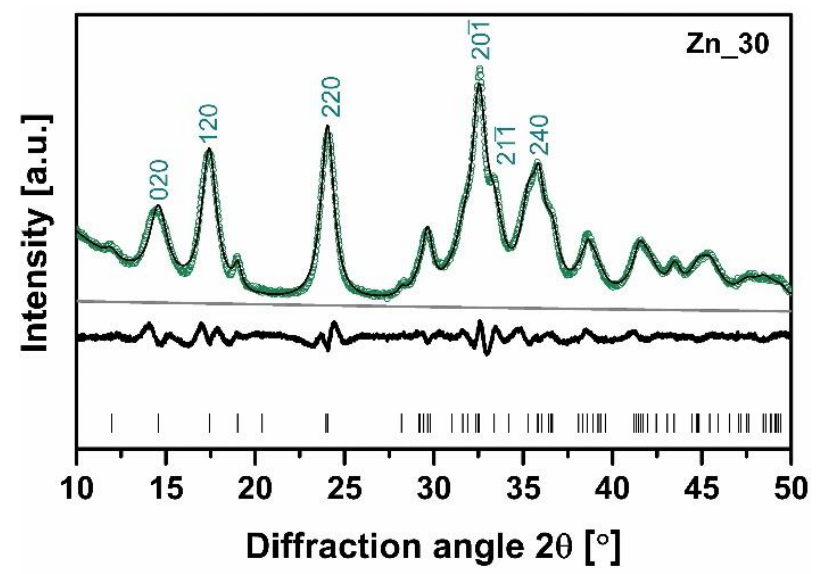

Fig. 2. Full pattern fit of the XRD pattern of synthetic zincian malachite sample Zn_30. The six most intense reflections are indexed. Experimental pattern (circles), calculated data (black line), background (grey line), difference (bottom curve) and peak positions (ticks) are given.

The lattice parameters $a, c$ and $\beta$ decrease with increasing $\mathrm{Zn}$ content, while the $b$-parameter increases. This overall trend applies as well for their analogs derived from the conventional synthesis procedure (co-precipitation and aging at $338 \mathrm{~K}$, circles in Fig. 3). The overall unit cell volumes of the former are slightly increased throughout the $x_{\mathrm{Zn}}$ range. Furthermore, the pure malachite analog deviates even more pronouncedly from the natural occurring mineral sample, especially in respect of the lattice parameters $a$ and $c$. Based on the established linear lattice parameter trends derived from the five phase-pure (zincian) malachite samples, the $\mathrm{Zn}$ content of the zincian malachite fraction of the biphasic sample $\mathrm{Zn} \_35$ was estimated. By linear regression, the overall best match is obtained for $x_{\mathrm{Zn}}$ : 0.26 (bottom filled square, Fig. 3). Interestingly, this point almost coincides with the upper limit of zinc incorporation observed for the conventional synthesis at $338 \mathrm{~K}$ [35]. In this work the formation of a minor aurichalcite by-phase $(\sim 5 \mathrm{wt} .-\%)$ is already observed for $\mathrm{Zn} \_20 \_$HT, indicating the critical amount of $x_{\mathrm{Zn}}: 0.2$ for a conventional binary co-precipitation (Fig. S6). 


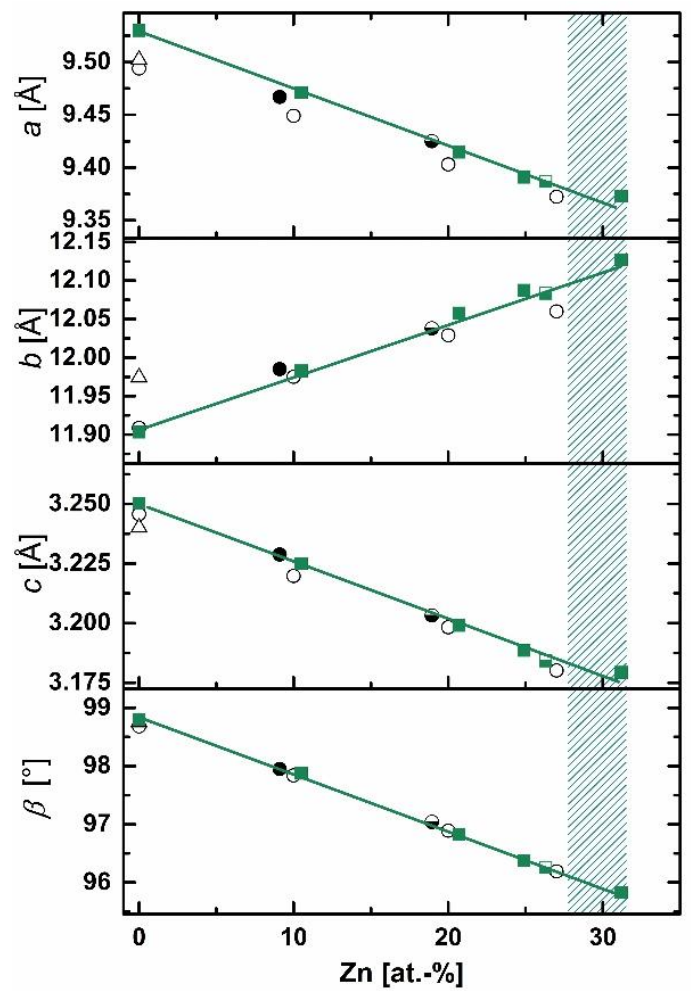

Fig 3. Trends of lattice parameters $a, b, c$ and $\beta$ in synthetic zincian malachite as a function of $\mathrm{Zn}$ content. Data of phase-pure samples of this study are given as green squares ( $\square$ ). The estimated $\mathrm{Zn}$ content of the zincian malachite phase of the biphasic $\mathrm{Zn}$ _ 35 is given as a bottom filled square (घ). Error bars of 3ESD (estimated standard deviations) are given but are not visible, as they are smaller than the size of the symbols used. The green hatched area highlights the increased upper limit of $\mathrm{Zn}$ incorporation into the zincian malachite structure. Circles ( $/ \mathrm{O}$ ) refer to zincian malachite samples prepared by the conventional synthesis route featuring co-precipitation and aging at $338 \mathrm{~K}$. The estimated $\mathrm{Zn}$ content of the zincian malachite phase of the biphasic Zn_20_HT sample is given as bottom filled circle ( Data for closed circles from this work and for open circles taken from[20]. Open triangles $(\triangle)$ represent the data for a mineral sample of malachite taken from [35].

It can be assumed that the expansion of the $\mathrm{Zn}$ incorporation into zincian malachite at $278 \mathrm{~K}$ is kinetically controlled and leads to a metastable "oversaturated" state, as represented by the Zn_30 sample (see also Fig. 1b). If, however, the $\mathrm{Zn}$ amount becomes too high, like in the $\mathrm{Zn} \_35$ case, the usual formation of a separate more $\mathrm{Zn}$ rich aurichalcite phase occurs. Apparently, once the aurichalcite phase forms, it provides a more favorable accommodation for the excess $\mathrm{Zn}$ than the oversaturated zincian malachite. Hence, the system snaps back into a more stable state which resembles the results from the conventional synthesis route. Developing another cooling/dosing recipe might lead to even more $\mathrm{Zn}$-enriched synthetic malachite structures. The specific surface area determined by the BET method [27] ( $\mathrm{SA}_{\mathrm{BET}}$ ) increases from $37 \mathrm{~m}^{2} \mathrm{~g}^{-1}$ (pure malachite sample) stepwise to its highest value of about $102 \mathrm{~m}^{2} \mathrm{~g}^{-1}$ for the $\mathrm{Zn} \_30$ sample (Table 1, Fig. 4). The observed trend is in accordance with the existing data in literature of conventional co-precipitated samples [36, 37], but the obtained absolute values are exceeded. In the case of the $\mathrm{Zn} \_20$ sample, the determined value is increased by a about $50 \%$, when compared to its HT-analogue (Table 1). The highest measured SA $\mathrm{BET}_{\mathrm{B}}\left(\mathrm{Zn} \_30\right)$ is even close to the value obtained when low amounts of ternary metal ions (e.g. $\mathrm{Al}^{3+}[38]$ ) are added to the binary $\mathrm{Cu} / \mathrm{Zn}$ system [39]. In case of the $\mathrm{Zn} \_35$ sample, the $\mathrm{SA}_{\mathrm{BET}}$ is decreased due to the presence of a binary Zlc/Aur phase mixture. Furthermore, the average anisotropic crystallite domain size decreases along both sample series (green triangles, Fig. 4). As the trends with $x_{\mathrm{Zn}}$ vary quantitatively for different crystal directions, the domain size values obtained for the first 20 reflections were averaged. Low-temperature co-precipitation evidently leads to the formation of smaller domain 
sizes, as indicated by the comparison of analogue samples of both series (e.g. Zn_10: $11 \mathrm{~nm}, \mathrm{Zn} \_10 \_H T: 33 \mathrm{~nm}$, Table 1).

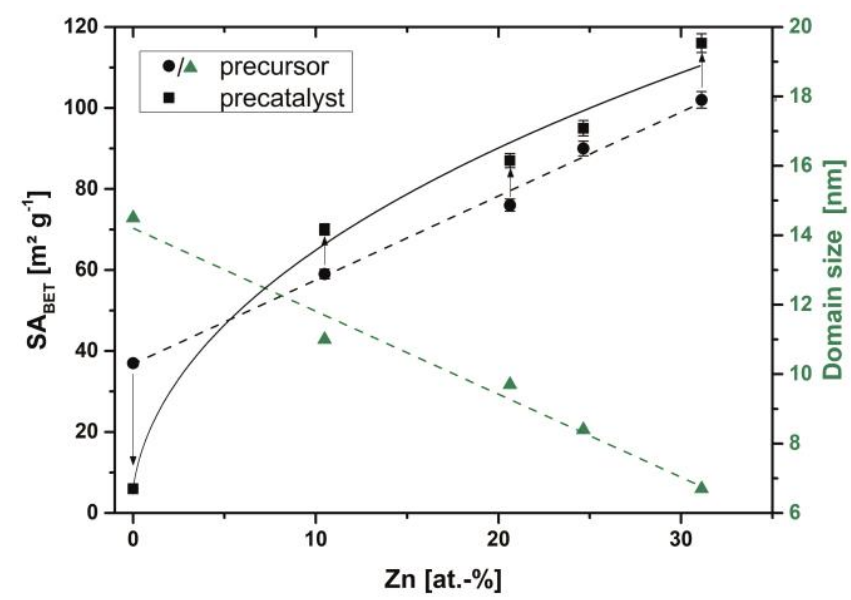

Fig. 4. BET-specific surface areas of precursor (black circle) and precatalyst (black square) samples as a function of $\mathrm{Zn}$ content. For the precursor samples, the corresponding average anisotropic crystallite domain sizes (green triangle) are given. Trend curves to guide the eye.

The morphology of the precursor samples was investigated by SEM analysis. The SEM micrograph of the $\mathrm{Zn} \_30$ sample is given in Fig. 5a. The morphology of the zincian malachite prepared at low temperature differs distinctly from the conventionally prepared samples. In the case of $\mathrm{Zn} \_20$, directly compared to the analogue sample prepared at $338 \mathrm{~K}$ (Zn_20_HT) the discrepancy in terms of the size of precipitated precursors aggregates is quite evident (Fig. S7). Low temperature formation of zincian malachite seems to lead to a less pronounced rod-like shape of the zincian malachite phase and generally to smaller aggregates. In addition, the smaller microstructure found in SEM is in line with the higher $\mathrm{SA}_{\mathrm{BET}}$ found within the whole sample set and additionally in accordance with the results from XRD. The uniform elemental distribution within the sample is verified by EDX elemental mapping (Fig. S8).

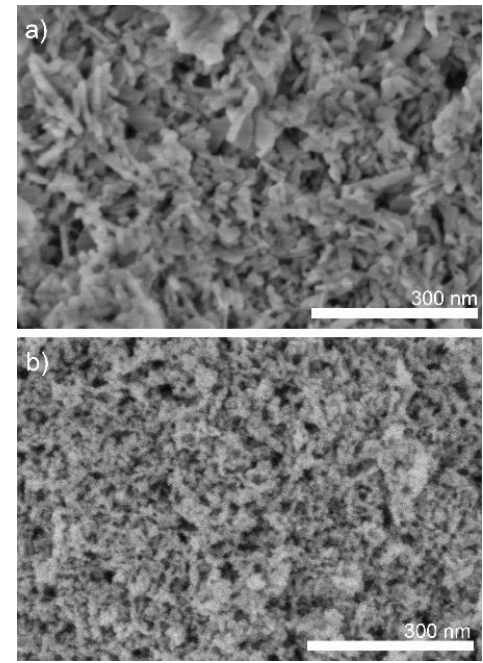

Fig. 5. SEM micrographs of zincian malachite precursor (a) and ex-zincian malachite precatalyst (b) Zn_30. 
The thermal decomposition of the precursors was investigated by thermogravimetric analysis (TGA) and evolved gas analysis (EGA). During calcination, the non-substituted malachite sample decomposes in a single event $[13,40]$ centered at around $572 \mathrm{~K}$, accompanied by simultaneous $\mathrm{H}_{2} \mathrm{O}(\mathrm{m} / \mathrm{z} 18)$ and $\mathrm{CO}_{2}(\mathrm{~m} / \mathrm{z}$ 44) release (Fig. S9a). However, two main decomposition steps are involved in the thermograms of all zincian malachite samples (Fig. S9) [13]:

$$
\begin{aligned}
2(\mathrm{Cu}, \mathrm{Zn})_{2}(\mathrm{OH})_{2} \mathrm{CO}_{3} \longrightarrow & (\mathrm{Cu}, \mathrm{Zn})_{4} \mathrm{O}_{3} \mathrm{CO}_{3} \\
& +2 \mathrm{H}_{2} \mathrm{O}+\mathrm{CO}_{2} \\
(\mathrm{Cu}, \mathrm{Zn})_{4} \mathrm{O}_{3} \mathrm{CO}_{3} \longrightarrow & 4(\mathrm{Cu}, \mathrm{Zn}) \mathrm{O}+\mathrm{CO}_{2}
\end{aligned}
$$

Desorption of $\mathrm{H}_{2} \mathrm{O}$ and $\mathrm{CO}_{2}$ from the surface occurs below $400 \mathrm{~K}$, followed by their concurrent liberation during the first decomposition step below $640 \mathrm{~K}$ (Equation 1) accounts for a mass loss of roughly $20 \%$. This leads to the formation of an intermediate phase $\mathrm{M}_{4} \mathrm{O}_{3} \mathrm{CO}_{3}(\mathrm{M}: \mathrm{Cu}, \mathrm{Zn})$ which is designated as high-temperature carbonate $\left(\mathrm{HT}-\mathrm{CO}_{3}\right)$ or anion-modified metal oxide [13, 40-42]. The sole release of $\mathrm{CO}_{2}$ during the second decomposition step at elevated temperatures above $640 \mathrm{~K}$ (Equation 2) leads to its transformation into the mixed $\mathrm{CuO} / \mathrm{ZnO}$. With increasing $\mathrm{Zn}$ content, its stability is increased which is indicated by the thermogravimetric patterns in Fig. 6. The decomposition is associated with a mass loss of $4-8$ wt.-\%. Zn-rich samples contain higher amounts of HT- $-\mathrm{CO}_{3}$, yet this trend levels of for $x_{\mathrm{Zn}} \geq 0.20$ and almost reaches the theoretical maximum (10\% mass loss) [42].

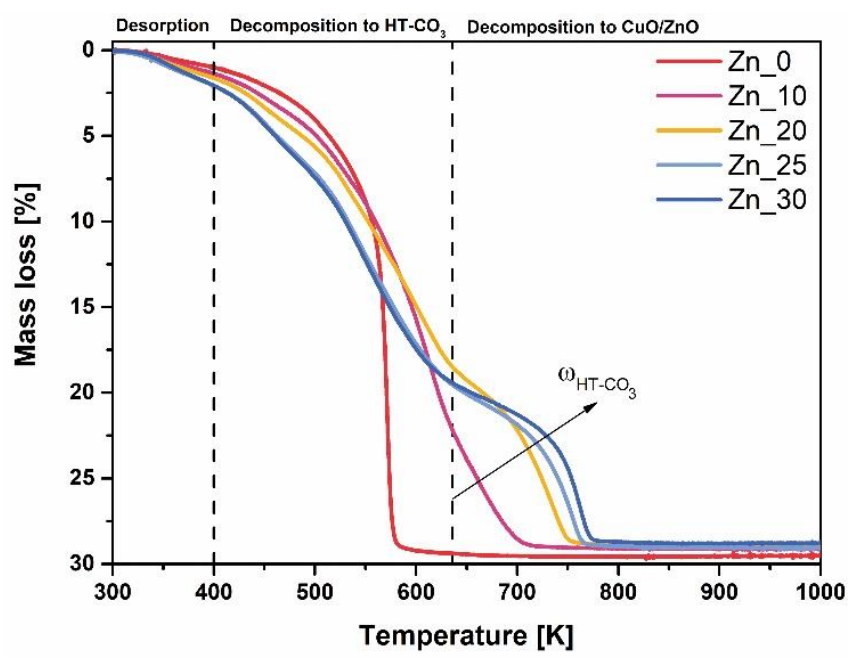

Fig. 6. Thermogravimetric decomposition patterns of prepared (zincian) malachite samples. The mass fraction $\omega$ of the $\mathrm{HT}-\mathrm{CO}_{3}$ rises with increasing $\mathrm{Zn}$ content. The stepwise decomposition of zincian malachite precursors to mixed $\mathrm{CuO} / \mathrm{ZnO}$ is highlighted. 


\subsection{Characterization of the precatalysts}

All phase-pure (zincian) malachite precursors were calcined at $603 \mathrm{~K}$ in $21 \% \mathrm{O}_{2} / \mathrm{Ar}$ (see exp. section). The obtained black powdered samples were subsequently analyzed by X-ray diffraction to identify their phase composition. The corresponding full pattern Rietveld fits are graphically shown in Fig. S11. A decrease in crystallinity is observed for increasing $\mathrm{Zn}$ content within the given sample series, as earlier described in the literature [17]. The applied thermal treatment leads to the decomposition of the initial (mixed) metal hydroxide carbonate phases yielding exclusively $\mathrm{CuO}$ particles in the case of the ex-malachite sample ( $\left.\mathrm{Zn} \_0\right)$ and mesoporous (Fig. S14) $\mathrm{CuO} / \mathrm{ZnO}$ phase mixtures in case of ex-zincian malachite samples. The former material hardly maintains its $\mathrm{SA}_{\mathrm{BET}}$ after calcination, while the specific surface area of the latter sample set is further raised by up to $18 \%$ (Table 1, Fig. 4). The observed incremental increase of $\mathrm{SA}_{\mathrm{BET}}$ is in line with a decrease of $\mathrm{Cu}$-content in the samples. Thus, it reaches its maximum at remarkable $116 \mathrm{~m}^{2} \mathrm{~g}^{-1}$ for the $\mathrm{Zn} \_30$ sample, comparable with the ternary system [39]. The given trend is in accordance with the data in literature [37]. The values obtained are of the same order of magnitude compared to the HT analogues prepared at $338 \mathrm{~K}$ (Table 1).

The precursors' overall morphology is preserved during calcination, as confirmed by SEM analysis on, e.g., the calcined $\mathrm{Zn} \_30$ sample (Fig. 5b). The uniform elemental distribution within the sample is still present, as verified by EDX elemental mapping (Fig. S12).

The reducibility of the aforementioned samples was investigated by temperature-programmed reduction (TPR) measurements up to $615 \mathrm{~K}$ in $5 \% \mathrm{H}_{2} /$ Ar. The reduction profiles of the precatalysts and selected HTanalogues are shown in Fig. 7a.
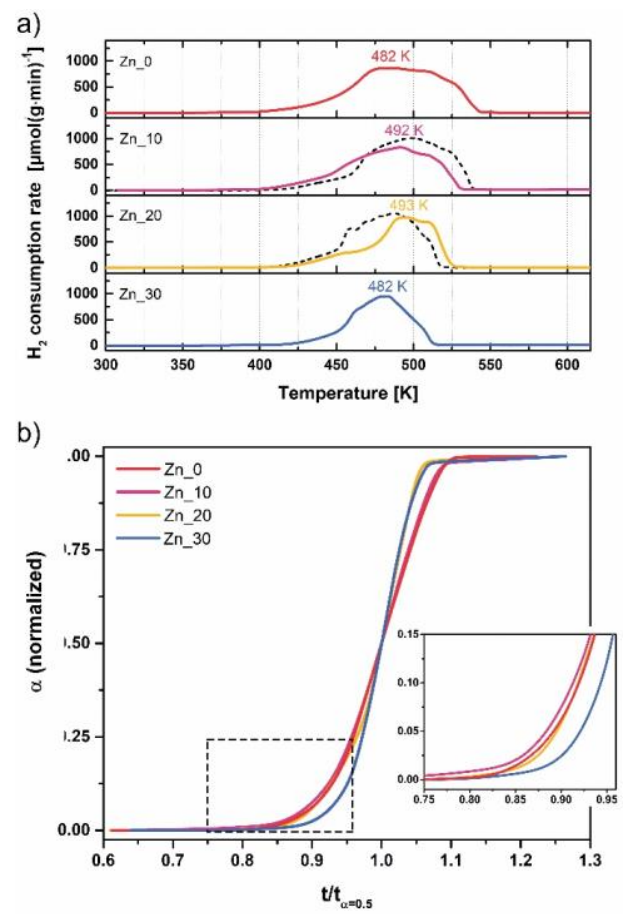

Fig. 7. TPR profiles of the precatalysts recorded at $6 \mathrm{Kmin}^{-1}$ in $5 \% \mathrm{H}_{2} / \mathrm{Ar}$ (a), respectively integrated TPR profiles normalized to time-fractions $\left(\mathrm{t} / \mathrm{t}_{a=0.5}\right)$ are given (b). TPR profiles of $\mathrm{Zn} \_10 \_\mathrm{HT}$ and $\mathrm{Zn} \_20 \_\mathrm{HT}$ precatalysts are given as dotted curves in Fig. 7a. 
The given data indicate a multi-step process which is representative for $\mathrm{Cu}$-containing materials. The reduction process from $\mathrm{Cu}^{\mathrm{II}} \mathrm{O}$ to elemental $\mathrm{Cu}^{0}$ is known to proceed via the kinetically stabilized $\mathrm{Cu}_{2}^{\mathrm{I}} \mathrm{O}$ intermediate $[39,43,44]$. All samples are fully reduced in a temperature range between $380 \mathrm{~K}$ and $550 \mathrm{~K}$. With increasing $\mathrm{Zn}$ content, the reduction temperature range narrows down to a $120 \mathrm{~K}$ window ( $\mathrm{Zn} \_30$ in Fig. 7a). The maximum $\mathrm{H}_{2}$ consumption rate of the reduction profile $\left(\mathrm{T}_{\max }\right)$ is in the range of $487 \pm 5 \mathrm{~K}$ for all samples. The reduction behavior is influenced by the presence of higher $\mathrm{Zn}$ contents in the samples as further emphasized by the presented $\alpha$-plots (Fig. 7b/Fig. S15). Here, the reduction progress $(\alpha)$ is given as the normalized integral curve of the TPR profiles as a function of temperature (Fig. S15) and normalized to time fractions $t / t_{\alpha=0.5}$ (Fig. 7b), respectively. The samples feature an overall similar reduction behavior (Fig. 7b), which is well described by a dispersion effect of $\mathrm{Cu}$ steered by the $\mathrm{Zn}$ content. With increasing $\mathrm{Zn}$ content, the dispersion of $\mathrm{Cu}$ gets higher, reaching its climax for $\mathrm{Zn} \_30$, represented in a shift of the reduction start to higher temperatures (higher $\mathrm{t} / \mathrm{t}_{\alpha=0.5}$ value in Fig. 7b). However, the autocatalytic character of the reduction process leads to its completion already at lower temperature (lower $\mathrm{t} / \mathrm{t}_{\alpha=0.5}$ value in Fig. $7 \mathrm{~b}$ ) for the smaller $\mathrm{CuO} \rightarrow \mathrm{Cu}_{2} \mathrm{O} \rightarrow \mathrm{Cu}$ particles.

\subsection{Characterization of the catalysts}

The final active catalysts were obtained after treatment of the precatalyst samples at $523 \mathrm{~K}$ in reductive atmosphere $\left(5 \% \mathrm{H}_{2} / \mathrm{Ar}\right)$. They were characterized for their specific surface area by using $\mathrm{N}_{2} \mathrm{O}-\mathrm{RFC}$ and $\mathrm{H}_{2}$-TA techniques (details see experimental section). The obtained specific surface areas are given in Table 1 and graphically presented in Fig. 8, respectively. In addition, XPS analysis was conducted to investigate the surface compositions (Table 2).

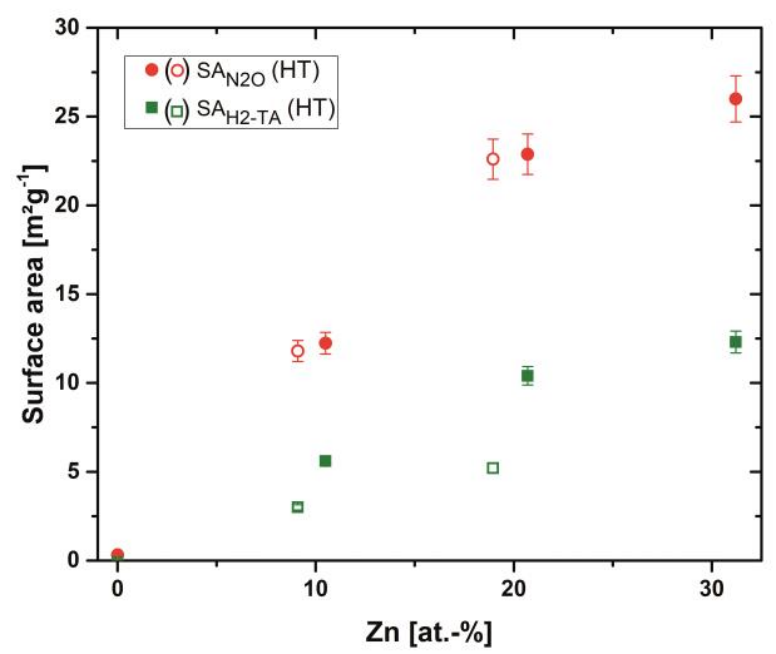

Fig. 8. Specific surface areas derived by $\mathrm{N}_{2} \mathrm{O}-\mathrm{RFC}$ and $\mathrm{H}_{2}-\mathrm{TA}$ as a function of $\mathrm{Zn}$ content. 
The specific surface area determined by $\mathrm{N}_{2} \mathrm{O}-\mathrm{RFC}$ increases with the content of $\mathrm{Zn}$ in the catalyst. The $\mathrm{Zn} \_10$ sample shows a specific surface area of about $12 \mathrm{~m}^{2} \mathrm{~g}^{-1}$, which is approximately 40 times larger compared to pure $\mathrm{Cu}$ alone $\left(\mathrm{Zn} \_0: 0.3 \mathrm{~m}^{2} \mathrm{~g}^{-1}\right)$. The increase of the $\mathrm{Zn}$ content leads to a further rise of the $\mathrm{SA}_{\mathrm{N} 2 \mathrm{O}}$ up to $23 \mathrm{~m}^{2} \mathrm{~g}^{-1}$ for $\mathrm{Zn} \_20$ and reaches a final value of $26 \mathrm{~m}^{2} \mathrm{~g}^{-1}$ for the $\mathrm{Zn} \_30$ sample. The increase of $S A_{\mathrm{N} 2 \mathrm{O}}$ with the $\mathrm{Zn}$ content is already well-known in literature [37]. The HT-samples share close resemblance to the low temperature co-precipitated samples exhibiting comparable specific $\mathrm{N}_{2} \mathrm{O}$ surface areas (Fig. 8) in line with the $\mathrm{SA}_{\mathrm{BET}}$ of the corresponding precatalysts. The results imply that the addition of $\mathrm{ZnO}$ increases the dispersion of $\mathrm{Cu}$ particles and thus the present specific surface area. Besides, it is known that the $\mathrm{N}_{2} \mathrm{O}-\mathrm{RFC}$ technique does not solely probe the $\mathrm{Cu}$ surface atoms but also reacts with oxygen vacancies in $\mathrm{ZnO}_{\mathrm{x}}$ and hence leads to an overestimation of the available $\mathrm{Cu}$ surface area $[30,31]$. Thus, to compensate for this, the specific $(\mathrm{Cu})$ surface area was measured using $\mathrm{H}_{2}$-TA as well. All obtained values determined by $\mathrm{H}_{2}$-TA are smaller than those measured by $\mathrm{N}_{2} \mathrm{O}-\mathrm{RFC}$ but follow the same trend. With increasing $\mathrm{Zn}$-content, the $\mathrm{H}_{2}$-TA values increase as well, from $5.6 \mathrm{~m}^{2} \mathrm{~g}^{-1}$ (Zn_10) up to $12.3 \mathrm{~m}^{2} \mathrm{~g}^{-1}$ for the $\mathrm{Zn} \_30$ sample. However, when catalysts with the same nominal $\mathrm{Zn}$ (and $\mathrm{Cu}$ ) content but co-precipitated at different temperatures are compared, another observation was made. About $87 \%$ higher $\mathrm{SA}_{\mathrm{H} 2 \mathrm{TA}}$ was obtained for $\mathrm{Zn} \_10\left(5.6 \mathrm{vs} 3.0 \mathrm{~m}^{2} \mathrm{~g}^{-1}\right)$ and an increase by $100 \%$ is present for the Zn_20 sample (10.4 vs $5.2 \mathrm{~m}^{2} \mathrm{~g}^{-1}$ ), when compared to its HT analogues. Thus, HT co-precipitation leads to a high fraction of inaccessible/ covered $\mathrm{Cu}$ moieties.

\begin{tabular}{|c|c|c|c|}
\hline \multirow[t]{2}{*}{ Sample } & Nominal & Bulk $^{[a]}$ & Surface $^{[\mathrm{b}]}$ \\
\hline & $\begin{array}{c}\mathrm{Zn} /(\mathrm{Cu}+ \\
\mathrm{Zn})\end{array}$ & $\mathrm{Zn} /(\mathrm{Cu}+\mathrm{Zn})$ & $\mathrm{Zn} /(\mathrm{Cu}+\mathrm{Zn})$ \\
\hline $\mathrm{Zn} \_10$ & 0.1 & 0.11 & $0.43\left(291 \%^{[\mathrm{c}]}\right)$ \\
\hline $\mathrm{Zn} \_20$ & 0.2 & 0.21 & $0.54\left(157 \%{ }^{[\mathrm{cl}]}\right)$ \\
\hline $\mathrm{Zn} \_30$ & 0.3 & 0.31 & $0.60\left(94 \%^{[\mathrm{c}]}\right)$ \\
\hline Zn_10_HT & 0.1 & 0.09 & $0.40\left(344 \%^{[\mathrm{c}]}\right)$ \\
\hline Zn_20_HT & 0.2 & 0.20 & $0.58\left(190 \%^{[\mathrm{c}]}\right)$ \\
\hline
\end{tabular}

[a] Determined by XRF measurements. [b] Determined by XPS analysis. [c]: Quantification of $\mathrm{Zn}$-enrichment at the surface based on the difference of the surface value of $\mathrm{Zn} /(\mathrm{Cu}+\mathrm{Zn})(\mathrm{XPS})$ and the bulk $\mathrm{Zn}$ content $(\mathrm{XRF})$ with respect to the bulk $\mathrm{Zn}$ value.

The contribution of oxidizable defects (probably oxygen vacancies) in the $\mathrm{ZnO}$ surface can be calculated from the difference of the aforementioned specific surface areas. The $\mathrm{Zn} \_30$ sample derived by low-temperature co-precipitation i.e. accounts for oxygen vacancies of about $53 \%$ of the $\mathrm{N}_{2} \mathrm{O}-\mathrm{RFC}$ capacity (Zn_20 with $55 \%$, $\mathrm{Zn} \_10$ with $53 \%$ ). According to the low $\mathrm{H}_{2}$-TA values of the HT-analogues of $\mathrm{Zn} \_10$ and $\mathrm{Zn}$ 20, these samples are even more rich in oxygen vacancies as they contribute about $75 \%$ to the measured $\mathrm{SA}_{\mathrm{N} 2 \mathrm{O}}$.

XPS analysis provides information on the relative surface composition of the reduced samples (Table 2). An enrichment of $\mathrm{Zn}$ on the surface is observed for all catalysts of the two sample-series. This phenomenon is well- 
known in the literature and explained by the SMSI of $\mathrm{Cu}$ and $\mathrm{ZnO}$, which leads to a partial coverage of the $\mathrm{Cu}$ surface by $\mathrm{ZnO}_{x}[7,8,39]$. The relative surface enrichment of $\mathrm{Zn}$ decreases with the increase of the overall $\mathrm{Zn}$ content (bulk). But still, the highest amount is present on the surface of the reduced $\mathrm{Zn} \_30$ sample. Again, the Zn_10_HT (344 \%) and Zn_20_HT (190 \%) samples show a higher relative surface enrichment of Zn, which is comparable to literature values synthesized by conventional co-precipitation techniques [37]. Further, the higher surface enrichment seems to be in line with the moieties of accessible $\mathrm{Cu}$ and/or $\mathrm{SA}_{\mathrm{H} 2-\mathrm{TA}}$. The low-temperature synthesis approach, accompanied by a high dispersion of $\mathrm{CuO}$ and $\mathrm{ZnO}$, leads in its reduced state to a moderately $\mathrm{Zn}$-enriched surface and an equally accessible amount of freely available and covered $\mathrm{Cu}$ moieties (Fig. 8, Table 1). This balanced surface constitution might serve as prerequisite for an optimized $\mathrm{Cu}-\mathrm{ZnO}$ interface and synergism.

\subsection{Catalytic Testing}

a)

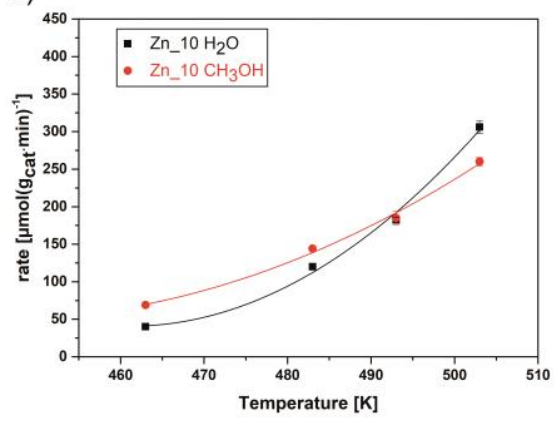

b)

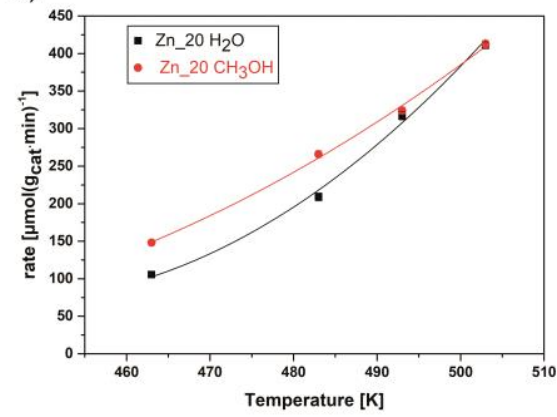

c)

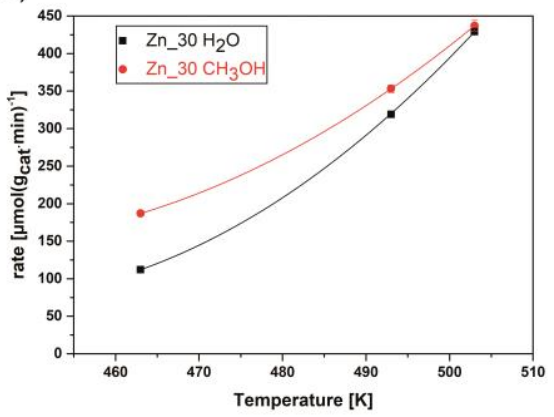

Fig. 9. Formation rates of methanol $\left(\mathrm{CH}_{3} \mathrm{OH}\right)$ and water $\left(\mathrm{H}_{2} \mathrm{O}\right)$ as a function of temperature and $\mathrm{Zn}$-content (a-c). Data for the mixed $\mathrm{Cu} / \mathrm{ZnO}$ catalysts $\mathrm{Zn} \_10$ (a), Zn_20 (b) and Zn_30 (c) are given. In the case of $\mathrm{Zn \_ 30} \mathrm{the} \mathrm{catalytic} \mathrm{testing} \mathrm{was} \mathrm{performed} \mathrm{at} \mathrm{three} \mathrm{different} \mathrm{temperatures.}$ Estimated standard deviations given. Trend curves are added to guide the eye.

Selected $\mathrm{Cu} / \mathrm{ZnO}$ catalysts derived from zincian malachite precursors were tested in methanol synthesis from syngas $\left(3.75 \mathrm{CO} / 18.75 \mathrm{CO}_{2} / 67.50 \mathrm{H}_{2} / 10.00 \mathrm{Ar}\right)$ between $463 \mathrm{~K}$ and $503 \mathrm{~K}$ at 40 bar. The feed composition corresponds to the result of an Aspen ${ }^{\circledR}$ simulation at $513 \mathrm{~K}$ and $40 \mathrm{bar}$, considering the (r)-WGS contribution cycling back the not converted reactants. The used gas ratio mirrors an equilibrated situation at the described conditions Fig. 9 presents the evolution of the formation rates of $\mathrm{CH}_{3} \mathrm{OH}$ and $\mathrm{H}_{2} \mathrm{O}$ for $\mathrm{Zn} \_10$ (a), $\mathrm{Zn} \_20$ (b) and $\mathrm{Zn} \_30$ (c) with the reaction temperature. At any given temperature, $\mathrm{CH}_{3} \mathrm{OH}$ formation increases with the $\mathrm{Zn}$ content of the catalyst, (i.e. at $493 \mathrm{~K}$, Fig. S16). This is in good agreement with the observed decrease of the apparent activation energies $\left(E_{\mathrm{A}}\right)$ of the $\mathrm{CH}_{3} \mathrm{OH}$ formation from $64 \pm 2.4 \mathrm{kJmol}^{-1}$ for the $\mathrm{Zn} \_10$, to $49 \pm 2.1 \mathrm{kJmol}^{-1}$ for the $\mathrm{Zn} \_20$ and $41 \pm 0.7 \mathrm{kJmol}^{-1}$ for the $\mathrm{Zn} \_30$. (see Arrhenius plots Fig. S17a and Table 1). Since $\mathrm{H}_{2} \mathrm{O}$ is a byproduct of the methanol formation from $\mathrm{CO}_{2}$, its reaction rate gives valuable information about the contribution of the (reverse-) water-gas shift (WGS) reaction. Generally, $\mathrm{H}_{2} \mathrm{O}$ formation rates lower than the $\mathrm{CH}_{3} \mathrm{OH}$ rates are explained by the occurrence of the WGS, since feeding $\mathrm{CO} / \mathrm{CO}_{2}$ mixtures $\mathrm{CO}_{2}$ is very likely the precursor for $\mathrm{CH}_{3} \mathrm{OH}$ [45]. According to the $\mathrm{H}_{2} \mathrm{O}$ formation shown in Fig. 9 a-c, the intersection points of the formation rates mark the contribution of the rWGS reaction. It is clearly shown that with increasing Zn content the rWGS 
reaction is suppressed and/or shifted to higher temperatures and the WGS reaction occurs (Fig. S18). Since stable formation rates at various temperatures allow for Arrhenius plots (Fig. S17b), the $E_{A}$ of the $\mathrm{H}_{2} \mathrm{O}$ formation are also calculated (Table 1). With increasing $\mathrm{Zn}$ content, the $E_{A}$ are decreasing. We tentatively interpreted these values as an approximation of the (r-)WGS contribution since $\mathrm{H}_{2} \mathrm{O}$ comes from a complex reaction network meaning high $E_{\mathrm{A}}$ of the $\mathrm{H}_{2} \mathrm{O}$ formation (e.g. Zn_10, $98 \pm 2.6 \mathrm{kJmol}^{-1}$ ) indicates a high activity in the rWGS reaction. This is further reflected in Table S3, where the product selectivities towards $\mathrm{CH}_{3} \mathrm{OH}$ were calculated and e.g. the Zn_10 catalyst shows a pronounced (r)-WGS contribution. In summary, with increasing Zn content of the catalyst, the $\mathrm{CH}_{3} \mathrm{OH}$ formation is also enhanced, while the $E_{\mathrm{A}}$ are continuously decreasing. In addition, the rWGS contribution is suppressed.

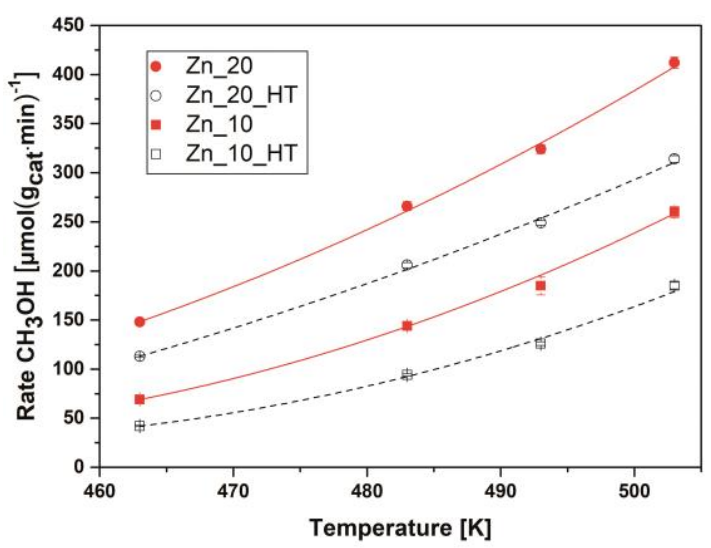

Fig. 10. Comparison of the methanol formation rates of $\mathrm{Cu} / \mathrm{ZnO}$ catalysts with nominal $\mathrm{Zn}$ loadings of 10 and 20 at.- $\%$, prepared by lowtemperature and high temperature (HT) co-precipitation of initially mixed metal hydroxy carbonate precursors.

To finally judge the advantages of the low temperature co-precipitation besides the higher catalytic activity for higher Zn moieties (quantitative effect), a direct comparison of the Zn_10 and Zn_20 samples with their HT analogues is necessary. Fig. 10 shows the corresponding $\mathrm{CH}_{3} \mathrm{OH}$ reaction rates at various temperatures. For both the $\mathrm{Zn} \_10$ and $\mathrm{Zn} \_20$ catalyst the activity is increased by 30-50\%. The calculated $E_{A}$ for the $\mathrm{CH}_{3} \mathrm{OH}$ formation are almost identical (Zn_20: 49 $2.1 \mathrm{kJmol}^{-1}$ and $\mathrm{Zn} \_20 \_H T: 50 \pm 2.4 \mathrm{kJmol}^{-1}$ ). This implies that the same kind of active sites are involved, but the number of sites is lower for the $\mathrm{Zn} \_20 \_H T$ catalysts. Since the $\mathrm{N}_{2} \mathrm{O}-\mathrm{RFC}$ values are identical, this discrepancy is explained by the lower $\mathrm{H}_{2}$-TA values. The almost identical values of the $\mathrm{Cu}-\mathrm{SA}$ and the oxygen vacancies of the low temperature sample (as difference between $\mathrm{N}_{2} \mathrm{O}-\mathrm{RFC}$ and $\mathrm{H}_{2}-\mathrm{TA}$, see discussion above) indicate a maximization of the available $\mathrm{Cu}-\mathrm{ZnO}$ interface, in agreement with the high degree of $\mathrm{Cu}$ dispersion. The low $\mathrm{H}_{2}$-TA value of e.g. $\mathrm{Zn} \_20 \_\mathrm{HT}$ represents a highly covered $\mathrm{Cu}$ surface (by $\mathrm{ZnO}_{\mathrm{x}}$ moieties) and thus a lower quantity of $\mathrm{Cu}-\mathrm{ZnO}$ interfacial contact. Since for the $\mathrm{rWGS}$ and $\mathrm{CH}_{3} \mathrm{OH}$ reaction different sites are involved,[46] the $\mathrm{CH}_{3} \mathrm{OH}$ sites might not be strongly $\mathrm{Zn}$-enriched. The $E_{\mathrm{A}}$ for water formation

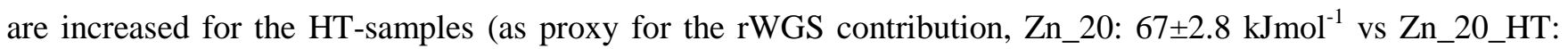
$80 \pm 2.9 \mathrm{kJmol}^{-1}$ ), evidencing that a strongly $\mathrm{Zn}$-enriched surface favors the unwanted rWGS side-reaction. Since binary $\mathrm{Cu} / \mathrm{ZnO}$ catalysts are prone to a pronounced deactivation at elevated temperatures [47] (see Fig. S19a), the question arises if the differently synthesized catalysts show the same deactivation behavior. In Fig. S19b the normalized $\mathrm{CH}_{3} \mathrm{OH}$ rates are compared at a longer time-on-stream and the activity curves decrease identically. 
Further, the Zn_20 catalysts were tested under industrially relevant conditions of 60 bar in syngas (Fig. S19c). Again, the $\mathrm{Zn} \_20$ catalyst is significantly more active than the Zn_20_HT and almost identical deactivation curves are obtained.

\section{Conclusions}

We herein report on a new route for the synthesis of pure $\mathrm{Zn}$ rich $\left(\mathrm{Cu}_{1-\mathrm{x}} \mathrm{Zn}_{\mathrm{x}}\right)_{2}(\mathrm{OH})_{2} \mathrm{CO}_{3}$. By the combination of low-temperature co-precipitation at $278 \mathrm{~K}$ and controlled aging at $338 \mathrm{~K}$ we obtained a series of novel zincian malachite samples. The upper limit of $\mathrm{Zn}$ incorporation into the malachite structure was successfully shifted up to $x_{\mathrm{Zn}}: 0.31$, the highest value reported in literature. The phase purity was verified by full-pattern Rietveld analysis on the precursors XRD data. The prepared material features small crystallite domain sizes and improved BET surface areas, which are even close to values obtained when low amounts of ternary metal ions $\left(\mathrm{Al}^{3+}\right)$ are added to the $\mathrm{Cu} / \mathrm{Zn}$ system. The precursors' morphology is drastically influenced by the developed synthesis route. In place of rod-like shaped crystallites we obtained less defined anisotropic interwoven crystallite materials. Their transformation to the corresponding $\mathrm{CuO} / \mathrm{ZnO}$ precatalysts lead to an incremental increase in specific surface area, which is in line with the gain in $\mathrm{Zn}$ content. Thus, it reaches its climax at remarkable $116 \mathrm{~m}^{2} \mathrm{~g}^{-1}$ for the $\mathrm{Zn} \_30$ sample, catching up with the ternary $\mathrm{Cu} / \mathrm{ZnO} / \mathrm{Al}_{2} \mathrm{O}_{3}$ system. The reduced binary catalysts feature high $\mathrm{Cu}$ surface areas of up to $11 \mathrm{~m}^{2} \mathrm{~g}^{-1}$, as determined by $\mathrm{H}_{2}$-TA. A high $\mathrm{Zn}$ content is desirable to further increase $\mathrm{Cu}$ dispersion, accordingly the highest value was observed for the $\mathrm{Zn} \_30$ sample. In addition, the dispersed $\mathrm{Cu} / \mathrm{ZnO}$ materials are rich in (oxidizable) defects in the $\mathrm{ZnO}$ surface, which is expected to be favorable for catalysis. The homogeneous $\mathrm{Cu}$-dispersion also leads to an equally accessible $\mathrm{Cu}$ surface and $\mathrm{ZnO}_{\mathrm{x}}$-sites, which is crucial for a maximized $\mathrm{Cu}-\mathrm{ZnO}$ interface. Increased activities in methanol synthesis were measured for these binary modeltype $\mathrm{Cu} / \mathrm{ZnO}$ catalysts, surpassing the co-precipitated HT-analogues and suppressing the rWGS contribution. The superior activities are also preserved under industrially relevant conditions and long times-on-stream. On the basis of this model system, a further shift of the $\mathrm{Zn}$ content of the zincin malachite precursor phase to values above 31 at.- $\%$ is tempting. In addition, to fully exploit the potential of the presented synthesis approach, it has to be extended by another metal oxide (i.e. adapted to the industrially relevant ternary $\mathrm{Cu} / \mathrm{ZnO} / \mathrm{Al}_{2} \mathrm{O}_{3}$ system). Generally, this low temperature synthesis approach serves as new tool for any co-precipitated crystalline materials and catalysts.

\section{Acknowledgements}

The authors thank J. Allan (TG), W. Frandsen and D. Ivanov (SEM), J. Plagemann and M. Hashagen (BET) as well as Dr. O. Timpe (XRF).

\section{Conflict of interest}

The authors declare no conflict of interest. 


\section{Appendix A. Supplementary data}

Supplementary material related to this article can be found in the online version at doi: XXXXX.

\section{References}

[1] W. Li, H. Wang, X. Jiang, J. Zhu, Z. Liu, X. Guo, C. Song, A short review of recent advances in CO2 hydrogenation to hydrocarbons over heterogeneous catalysts, RSC Advances, 8 (2018) 7651-7669. [2] J.B. Hansen, P.E. Højlund Nielsen, Methanol Synthesis, Handbook of Heterogeneous Catalysis, Wiley-VCH Verlag GmbH \& Co. KGaA2008, pp. 2920-2949.

[3] O. Tursunov, L. Kustov, A. Kustov, A Brief Review of Carbon Dioxide Hydrogenation to Methanol Over Copper and Iron Based Catalysts, Oil \& Gas Science and Technology - Rev. IFP Energies nouvelles, 72 (2017) 30.

[4] G.A. Olah, A. Goeppert, G.K.S. Prakash, Beyond Oil and Gas: The Methanol Economy, Wiley2009. [5] G.C. Chinchen, M.S. Spencer, K.C. Waugh, D.A. Whan, Promotion of methanol synthesis and the water-gas shift reactions by adsorbed oxygen on supported copper catalysts, J. Chem. Soc., Faraday Trans. 1, 83 (1987) 2193-2212.

[6] S. Zander, E.L. Kunkes, M.E. Schuster, J. Schumann, G. Weinberg, D. Teschner, N. Jacobsen, R. Schlögl, M. Behrens, The Role of the Oxide Component in the Development of Copper Composite Catalysts for Methanol Synthesis, Angew. Chem. Int. Ed., 52 (2013) 6536-6540.

[7] M. Behrens, F. Studt, I. Kasatkin, S. Kühl, M. Hävecker, F. Abild-Pedersen, S. Zander, F. Girgsdies, P. Kurr, B.-L. Kniep, M. Tovar, R.W. Fischer, J.K. Nørskov, R. Schlögl, The Active Site of Methanol Synthesis over Cu/ZnO/Al2O3 Industrial Catalysts, Science, 336 (2012) 893-897.

[8] T. Lunkenbein, J. Schumann, M. Behrens, R. Schlögl, M.G. Willinger, Formation of a ZnO Overlayer in Industrial $\mathrm{Cu} / \mathrm{ZnO} / \mathrm{Al} 2 \mathrm{O} 3$ Catalysts Induced by Strong Metal-Support Interactions, Angew. Chem. Int. Ed., 54 (2015) 4544-4548.

[9] K. Klier, Methanol Synthesis, in: H.P. D.D. Eley, B.W. Paul (Eds.) Adv. Catal., Academic Press1982, pp. 243-313.

[10] G.C. Chinchen, P.J. Denny, J.R. Jennings, M.S. Spencer, K.C. Waugh, Synthesis of Methanol, Appl. Catal., 36 (1988) 1-65.

[11] F. Schüth, M. Hesse, K.K. Unger, Precipitation and Coprecipitation, Handbook of Heterogeneous Catalysis, Wiley-VCH Verlag GmbH \& Co. KGaA2008.

[12] J.L. Li, T. Inui, Characterization of precursors of methanol synthesis catalysts, copper/zinc/aluminum oxides, precipitated at different pHs and temperatures, Appl. Catal., A. , 137 (1996) 105-117.

[13] B. Bems, M. Schur, A. Dassenoy, H. Junkes, D. Herein, R. Schlögl, Relations between Synthesis and Microstructural Properties of Copper/Zinc Hydroxycarbonates, Chem. Eur. J., 9 (2003) 2039-2052. [14] C. Baltes, S. Vukojević, F. Schüth, Correlations between synthesis, precursor, and catalyst structure and activity of a large set of $\mathrm{CuO} / \mathrm{ZnO} / \mathrm{Al} 2 \mathrm{O} 3$ catalysts for methanol synthesis, J. Catal., 258 (2008) 334-344.

[15] M. Behrens, D. Brennecke, F. Girgsdies, S. Kißner, A. Trunschke, N. Nasrudin, S. Zakaria, N.F. Idris, S.B.A. Hamid, B. Kniep, R. Fischer, W. Busser, M. Muhler, R. Schlögl, Understanding the complexity of a catalyst synthesis: Co-precipitation of mixed $\mathrm{Cu}, \mathrm{Zn}, \mathrm{Al}$ hydroxycarbonate precursors for $\mathrm{Cu} / \mathrm{ZnO} / \mathrm{Al} 2 \mathrm{O} 3$ catalysts investigated by titration experiments, Appl. Catal., A392 (2011) 93-102.

[16] S.-i. Fujita, Y. Kanamori, A.M. Satriyo, N. Takezawa, Methanol synthesis from CO2 over Cu/ZnO catalysts prepared from various coprecipitated precursors, Catal. Today, 45 (1998) 241-244. 
[17] G.C. Shen, S.-I. Fujita, N. Takezawa, Preparation of precursors for the $\mathrm{Cu} / \mathrm{ZnO}$ methanol synthesis catalysts by coprecipitation methods: Effects of the preparation conditions upon the structures of the precursors, J. Catal., 138 (1992) 754-758.

[18] D. Waller, D. Stirling, F.S. Stone, M.S. Spencer, Copper-zinc oxide catalysts. Activity in relation to precursor structure and morphology, Faraday Discuss. Chem. Soc., 87 (1989) 107-120.

[19] S. Zander, B. Seidlhofer, M. Behrens, In situ EDXRD study of the chemistry of aging of coprecipitated mixed $\mathrm{Cu}, \mathrm{Zn}$ hydroxycarbonates - consequences for the preparation of $\mathrm{Cu} / \mathrm{ZnO}$ catalysts, Dalton Trans., 41 (2012) 13413-13422.

[20] M. Behrens, F. Girgsdies, Structural Effects of Cu/Zn Substitution in the Malachite-Rosasite System Z. Anorg. Allg. Chem., 636 (2010) 919-927.

[21] M. Behrens, F. Girgsdies, A. Trunschke, R. Schlögl, Minerals as Model Compounds for Cu/ZnO Catalyst Precursors: Structural and Thermal Properties and IR Spectra of Mineral and Synthetic (Zincian) Malachite, Rosasite and Aurichalcite and a Catalyst Precursor Mixture, Eur. J. Inorg. Chem., 2009 (2009) 1347-1357.

[22] M.M. Günter, T. Ressler, B. Bems, C. Büscher, T. Genger, O. Hinrichsen, M. Muhler, R. Schlögl, Implication of the microstructure of binary $\mathrm{Cu} / \mathrm{ZnO}$ catalysts for their catalytic activity in methanol synthesis, Catal. Lett., 71 (2001) 37-44.

[23] A.M. Pollard, M.S. Spencer, R.G. Thomas, P.A. Williams, J. Holt, J.R. Jennings, Georgeite and azurite as precursors in the preparation of co-precipitated copper/zinc oxide catalysts, Appl. Catal., A, 85 (1992) 1-11.

[24] M. Behrens, Meso- and nano-structuring of industrial $\mathrm{Cu} / \mathrm{ZnO} /(\mathrm{Al} 2 \mathrm{O} 3)$ catalysts, J. Catal., 267 (2009) 24-29.

[25] P. Stephens, Phenomenological model of anisotropic peak broadening in powder diffraction, J. Appl. Cryst., 32 (1999) 281-289.

[26] X. Li, T. Lunkenbein, J. Krohnert, V. Pfeifer, F. Girgsdies, F. Rosowski, R. Schlogl, A. Trunschke, Hydrothermal synthesis of bi-functional nanostructured manganese tungstate catalysts for selective oxidation, Faraday Discuss., 188 (2016) 99-113.

[27] S. Brunauer, P.H. Emmett, E. Teller, Adsorption of Gases in Multimolecular Layers, J. Am. Chem. Soc., 60 (1938) 309-319.

[28] E.P. Barrett, L.G. Joyner, P.P. Halenda, The Determination of Pore Volume and Area Distributions in Porous Substances. I. Computations from Nitrogen Isotherms, J. Am. Chem. Soc., 73 (1951) $373-$ 380.

[29] G.C. Chinchen, C.M. Hay, H.D. Vandervell, K.C. Waugh, The measurement of copper surface areas by reactive frontal chromatography, J. Catal., 103 (1987) 79-86.

[30] S. Kuld, C. Conradsen, P.G. Moses, I. Chorkendorff, J. Sehested, Quantification of Zinc Atoms in a Surface Alloy on Copper in an Industrial-Type Methanol Synthesis Catalyst, Angew. Chem., 126 (2014) 1-6.

[31] M.B. Fichtl, J. Schumann, I. Kasatkin, N. Jacobsen, M. Behrens, R. Schlögl, M. Muhler, O. Hinrichsen, Counting of Oxygen Defects versus Metal Surface Sites in Methanol Synthesis Catalysts by Different Probe Molecules, Angew. Chem. Int. Ed., 53 (2014) 7043-7047.

[32] D.A.M. Monti, A. Baiker, Temperature-programmed reduction. Parametric sensitivity and estimation of kinetic parameters, J. Catal., 83 (1983) 323-335.

[33] J.J. Yeh, I. Lindau, Atomic subshell photoionization cross sections and asymmetry parameters: $1 \leqslant$ $\mathrm{Z} \leqslant 103$, Atom Data Nucl. Data Tables, 32 (1985) 1-155.

[34] K.P. de Jong, Synthesis of Solid Catalysts, Wiley2009.

[35] F.J. Zigan, W. Schuster, H. D., Verfeinerung der Struktur von Malachit, Cu2(OH)2CO3, durch Neutronenbeugung, Z. Kristallog., 142 (1977) 412-426.

[36] Y. Okamoto, K. Fukino, T. Imanaka, S. Teranishi, Surface characterization of copper(II) oxidezinc oxide methanol-synthesis catalysts by x-ray photoelectron spectroscopy. 1. Precursor and calcined catalysts, J. Phys. Chem., 87 (1983) 3740-3747. 
[37] C. Álvarez Galván, J. Schumann, M. Behrens, J.L.G. Fierro, R. Schlögl, E. Frei, Reverse water-gas shift reaction at the $\mathrm{Cu} / \mathrm{ZnO}$ interface: Influence of the $\mathrm{Cu} / \mathrm{Zn}$ ratio on structure-activity correlations, Appl. Catal. B., 195 (2016) 104-111.

[38] M. Behrens, S. Zander, P. Kurr, N. Jacobsen, J. Senker, G. Koch, T. Ressler, R.W. Fischer, R. Schlögl, Performance Improvement of Nanocatalysts by Promoter-Induced Defects in the Support Material: Methanol Synthesis over Cu/ZnO:Al, J. Am. Chem. Soc., 135 (2013) 6061-6068.

[39] J. Schumann, T. Lunkenbein, A. Tarasov, N. Thomas, R. Schlögl, M. Behrens, Synthesis and Characterisation of a Highly Active Cu/ZnO:Al Catalyst, ChemCatChem, 6 (2014) 2889-2897.

[40] G.J. Millar, I.H. Holm, P.J.R. Uwins, J. Drennan, Characterization of precursors to methanol synthesis catalysts Cu/ZnO system, J. Chem. Soc., Faraday Trans., 94 (1998) 593-600.

[41] T.M. Yurieva, Catalyst for methanol synthesis: Preparation and activation, React. Kinet. Catal. Lett., 55 (1995) 513-521.

[42] A. Tarasov, J. Schumann, F. Girgsdies, N. Thomas, M. Behrens, Thermokinetic investigation of binary $\mathrm{Cu} / \mathrm{Zn}$ hydroxycarbonates as precursors for $\mathrm{Cu} / \mathrm{ZnO}$ catalysts, Thermochim. Acta, 591 (2014) 19.

[43] A. Tarasov, S. Kühl, J. Schumann, M. Behrens, Thermokinetic study of the reduction process of a CuO/ZnAl2O4 catalyst, High Temp. - High Pressures, 42 (2013) 377-386.

[44] S. Kühl, A. Tarasov, S. Zander, I. Kasatkin, M. Behrens, Cu-Based Catalyst Resulting from a $\mathrm{Cu}, \mathrm{Zn}, \mathrm{Al}$ Hydrotalcite-Like Compound: A Microstructural, Thermoanalytical, and In Situ XAS Study, Chem. Eur. J., 20 (2014) 3782-3792.

[45] F. Studt, M. Behrens, E.L. Kunkes, N. Thomas, S. Zander, A. Tarasov, J. Schumann, E. Frei, J.B. Varley, F. Abild - Pedersen, J.K. Nørskov, R. Schlögl, The Mechanism of CO and CO2 Hydrogenation to Methanol over $\mathrm{Cu}$ - Based Catalysts, ChemCatChem, 7 (2015) 1105-1111.

[46] E.L. Kunkes, F. Studt, F. Abild-Pedersen, R. Schlögl, M. Behrens, Hydrogenation of CO2 to methanol and $\mathrm{CO}$ on $\mathrm{Cu} / \mathrm{ZnO} / \mathrm{Al} 2 \mathrm{O} 3$ : Is there a common intermediate or not?, Journal of Catalysis, 328 (2015) 43-48.

[47] J. Schumann, A. Tarasov, N. Thomas, R. Schlögl, M. Behrens, Cu,Zn-based catalysts for methanol synthesis: On the effect of calcination conditions and the part of residual carbonates, Applied Catalysis A: General, 516 (2016) 117-126. 